\title{
Ethics And Values In The Context Of Teaching Excellence In The Changing World Of Education
}

Richard L. Henderson, University of the Incarnate Word, USA Absael Antelo, University of the Incarnate Word, USA

Norman St. Clair, University of the Incarnate Word, USA

\begin{abstract}
This article focused on the ethical problems associated with teaching in a transnational or multicultural environment. Authors offer a review of related literature, as well as extensive global teaching experience, to proffer a model that is designed to allow professional educators to maintain excellence in teaching in the problematic context. Recommendations for research are also offered as part of the conclusions (Henderson).
\end{abstract}

Keywords: Ethics in Higher Education, Teaching Ethics, Ethical Teaching, Instructional Ethics, Ethics in Andragogy

\section{INTRODUCTION}

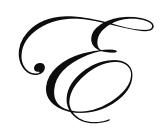

xcellence in teaching is difficult to achieve in any context; in a multicultural context, it is monumentally difficult. This writing is guided by international and multicultural teaching experiences, as well as a review of the literature, related to ethical teaching practices in culturally diverse contexts. Gaining knowledge and acquiring positive experiences about the importance of diversity of ethics and values in secondary and higher education is increasingly important in today's global education society. Even an expressed adherence to a rational model is plagued with the question of what constitutes the most appropriate rationality. We know that what is considered rational varies even among individuals. Therefore, the variation present in the context of multiple cultures is even more problematic. The ethics of teaching a culturally diverse group poses a number of problems.

In an increasingly common example, a teacher must decide to allow class participants to enter into cooperative educational practices, or conversely, to require class members to remain fiercely independent as is dictated by the conventional U. S. scholarship tradition. Ethics in the context of student scholarship is not far from ethics or values in the lives of those we teach. In the context of international or global education, how we decide the ethical standards that are appropriate for endorsement, instruction and modeling are critically important. The purpose of this work, therefore, is to explore some possible options and proffer a position that may be acceptable in a variety of contexts.

The content and method of educating people worldwide in this century is changing at a remarkable pace due to a variety of factors defining modern societies. The impact of technology, transportation, communication, and culture on human knowledge in daily life are significantly different from one decade to the next, from one year to the next, and in some cases, from one day to the next. In the institution of education, this probably should be accepted as a normal expectation because education itself is designed, in part, to produce behavioral change and has, as one of its primary purposes, the teaching of change. However, in spite of that expressed purpose, we do seem to have to continuously guard against teaching for obsolescence. Speaking of obsolescence, teaching methods for many seem to have evolved at a much slower pace than other aspects of education. 
Extensive teaching experience suggests that providing discipline-bound learning experiences, with an eye toward ethics, may be used to teach students critically important ideas and important issues. Specific contents may call for the use of particular methods depending on the situation and the intended learning outcomes. The nature of the concept or idea may tell us that teacher-centered strategies are not appropriate in every case or even most cases. Learning strategies based on student experiences may be the most appropriate methodological design for learning particular ideas. While knowledge, skill levels, and functional development may be well served by teacher expertise, ideas or understanding that require a behavioral response that is driven, in part, by affect or emotional intelligence, may require teaching methods and learning environments based on student experience, simulated or real, but in any case, heavily reliant on student participation and teacher facilitation.

Simply put, although intellectual understanding gained through lecture or reading materials may be critically important, the resulting knowledge may also foster an expected ethical behavior or practice that may only be completely understood by living and working through difficult situations presented in life's circumstances. This perspective also suggests the proposition that students do not learn simply because we teach them, but also because they are involved or engaged in their own educational process. When students are empowered, by teachers, to have some control over their learning resources, it is more likely that they will employ meaningful learning activities and teachers may actually become real facilitators, helping students to navigate difficult, but realistic, situations that require them to apply ethical principles. Teachers may then concentrate on guiding behavior and decision making toward ethical circumstances.

The teaching challenge then becomes the decisions about which student-centered activities will be most effective and how teacher-centered or rule student-centered, albeit ethically bound learning strategies, may replace centered strategies. Teaching strategies may then become instructional planning decisions that fully embrace the variables which control learning behavior, including emotional and ethical considerations, as well as intellectual and academic outcomes.

This reconfigured teaching strategy also allows cross-cultural communication to be an integral part of the learning process and the classroom setting becomes one in which culturally diverse students may engage in the analyses and resulting solutions to learning problems that frequently include ethical issues. Different cultural perspectives are brought to bear on a variety of issues and the learning process is enhanced as a result of the multiple perspectives provided by the cultural diversity of the group. The positive cultural strengths of each participating member of the learning situation also have a much better chance of emerging in the final solution to problems and in the learning outcomes. Moreover, the beliefs, values, norms, and traditions advocated by each member of the learning group help to create a knowledge base that, culturally speaking, is universally acceptable and respectful. Much of the literature related to ethics in the teaching process centers on the problems of academic dishonesty, as is evident below. However, as is evident, that problem also stems from cultural differences and learning styles that have developed in a much different way than those of most North American students in the U.S.

\section{LITERATURE}

The notion of academic integrity is receiving a great deal of attention in literature due to the influx of international students in U.S. classrooms and the resulting clash of cultural norms (Lathrop, 2000; Harris, 2001; Hunt, 2003). Research suggests that issues around academic integrity are reaching epidemic proportions at institutions of higher learning in America, perhaps due to this mixing of academic cultures. The research studied for this brief review of literature centers on high-context international student populations and the various forms of academic dishonesty, while investigating the cultural origins of this phenomenon.

Graham et al (1994) noted in a study of academic integrity that over $90 \%$ of students had taken part in some form of cheating during their course of study. Cummings et al (2002) also referenced numerous studies reporting cheating rates at over $70 \%$, while Rennie and Crosby (2001) reported that $61 \%$ of the students they surveyed indicated no problem with copying from a source as long as they cited it in their list of references. Cameron (2004) suggested the causes for a lack of academic integrity range from a rejection of academic values to misunderstanding of the complexity of terms and conventions. Other contributing factors in academic dishonesty are cited as inadequate language skills and cultural misunderstandings, leading to the misuse of academic resources 
(Angelova \& Riazantseva, 1999; Ashworth \& Bannister, 1997). Angelil-Carter (2000) supports this observation, suggesting that there is a lack of clarity within a given institution about what constitutes academic dishonesty and how these issues are enforced at an institutional level.

Other studies also suggest that plagiarism is not the only concern when it comes to academic integrity. Other forms of academic dishonesty include cheating on exams, taking cheat sheets into exams, unauthorized collaboration in coursework, and submitting the same class product more than once, without proper disclosure to the professors involved (Hunt, 2003; Drinan, 1999). However, when it comes to plagiarism, Carroll (2002) noted that most students are unsure how to define it. They do not plagiarize with the intent to deceive; rather, they are trying to find a way to manage their workload. Students from different cultures engage in academic dishonesty as a result of their approach to learning (Carroll, 2002).

This is evident in studies that focus on high-context cultures from the East, suggesting their learning styles are contrary to their Western counterparts (Pennycook, 1996; Angelova \& Raizantsevn, 1999; Biggs, 1994; Carroll \& Appleton, 2001). In most Asian countries, learning and assessment generally focus on textbook content and ability to recall information in a rote fashion, as opposed to the Western tradition of low-context, discussion-based methodologies (Hall, 1990). The consequences of this difference, according to Pennycook (1996), become apparent when students from Asia enter into Western higher education. Students from these countries, especially China, consider verbatim usage of another author's words as a form of respect; it is difficult for these students to share opinions in their own words. Carroll and Appleton (2001) found that students from Asia plagiarize due to a lack of experience in essay writing because higher education in their countries rely exclusively on examinations stemming from textbooks. Hofstede (2001) also mentioned the issue of uncertainty, which indicates the extent to which members of a given society feel threatened by uncertain or unfamiliar situations. O'Donoghue (1996) and Biggs (1994) illustrate this point in their respective research. Fear of failure places a great deal of pressure on students to do well. This fear is further compounded when considering how these students' education might be funded (i.e. family, government, or business). Students from Asia are also challenged by the feeling that they cannot improve on what was already published and prefer to use the original work (Biggs, 1994; Fox, 1994; Carroll \& Appleton, 2001). These are considerable differences in cultural paradigms according to Hofstede and the transition from a highcontext academic setting to an American academic setting presents major challenges for students. Hofstede maintains that people do not learn, but rather inherit, culture; it comes from one's social environment. Therefore, the real question may be, "How may these differences that often result in ethical dilemmas for teachers and students find resolutions that do not negatively affect the learning process for some or all of the students?"

A recent article in the Chronicle Review seems a good forward for any position that would center on cultural and ethical principles. Gordon Marino stated that people who presume to teach or influence ethics should help their students be honest with themselves about their own interest. He proffered that the Socratic curriculum of coming to know yourself is critical.

Marino also stated that it is hard psychological work to accomplish such a goal:

Unless our students learn to examine themselves and what they really value, their command of ethical theories and their ability to think about ethics form diverse perspectives are not likely to bring them any closer to being willing and able to do the right thing." concluded Marino. (Marino, 2004, p. b5)

As is evident in the literature above, much of the recent literature is devoted to Asian or "Pacific Rim" foreign national students. However, it may well be due the fact that they represent a group that not only seeks U.S. education, but finds it significantly different than their earlier native experiences.

\section{RECOMMENDED MODEL}

Experience as teachers allows us to understand not only the power of knowing yourself, but also the critical necessity of bringing tacitly-assumed notions of right and wrong to consciousness, prior to placing value on the beliefs of others. Therefore, the first step in the process of reformulating the principles of teaching, which guides one's behavior as a professional teacher in a transnational or multicultural context, is self-examination. 
Moreover, since learning is indeed a complex social process that includes students, as well as teachers, it is incumbent on all of the members of any learning environment to enter into self-examination individually before attempting to understand or value the diversity of values and ethical principles that are likely to be found in a multinational or multicultural classroom context. Following this proposed self-reflection and conscience examination, one may liken the process to an interfaith or ecumenical meeting in which members of the community or group frequently withhold their opinion, and therefore, their judgment relative to the contributions of members of the group. Additionally, the membership, led by the teacher's example, must also withhold their respective judgments about individual contributions to the class, as well as methodologies, both teacher-centered and studentcentered, that are planned by the teacher or the group to enhance the learning process.

In order for the teacher to serve as the exemplary leader of the group, extra effort on her/his part is, of course, required. The teacher must take the preparation time to study and understand the cultures, including their respective ethics that are present in the individual members of the group. This step is critical to an effective process as it is the teacher who sets the tone, provides the example, and facilitates the learning methodology that is to be undertaken. Summary cultural studies must be accomplished, as well as conversations with colleagues - preferably from the cultures represented in the prospective classroom group - and finally, if possible, conversations with the prospective class members - in order to ascertain an understanding of their individual cultural and educational experiences, both native and international.

In teaching practice, one approach that has been extremely instructive is to begin the classroom experience with a shared self-reflection exercise. This process, when used effectively, has provided a basis for individuals to derive self-understanding as well as developing tolerance and understanding of classmates. Specifically, as advocated by Henderson in earlier work, using a process that brings to consciousness the key factors that help to form a person's values is instructive in understanding your own ethics, as well as those of the people with whom you are working (Henderson 1990). The process also has the effect of enhancing the degree of tolerance with which one views the ideas and values of others. The caution is that it must be undertaken with care and only by those who have some experience and training in social-psychological processes. helpful.

A model to serve the ethics of teaching in a multinational or multicultural classroom circumstance may be

Such a model would include the following preparation elements:

1. Review, analyze and incorporate information about the cultural, ethnic and educational circumstances of all of the groups represented in an anticipated classroom circumstance.

2. Review of positive or negative relationships between elements of the background circumstances listed above and the anticipated teaching methodologies planned for use in the anticipated class.

3. Undertake an individual self-reflection process on the part of the teacher in preparation for leading such a process as an opening classroom activity.

4. Include a planned self-reflection exercise to begin the class that will allow all participants to gain selfawareness and awareness of others with whom they will be working.

5. Reflection and practice with respect to responding to perspectives and ethical practices that are contrary to your own tacitly adopted system of beliefs.

6. Review the match or mismatch between specific values and practices found among international or diverse cultural groups that are scheduled for participation in the anticipated class.

7. Review the teaching strategies and methods that are likely to enhance engagement and participation on the part of international or diverse cultural groups within the anticipated class.

8. Review the teaching delivery systems that may be helpful for students with limited English capabilities.

Clearly, the elements contained in the model described above do not supplant the normal course planning and teaching process. They are simply additional considerations that must be made when the classroom population includes multinational or multicultural groups. 
Graph 1

\section{Ethical Teaching in the Context of Excellence}

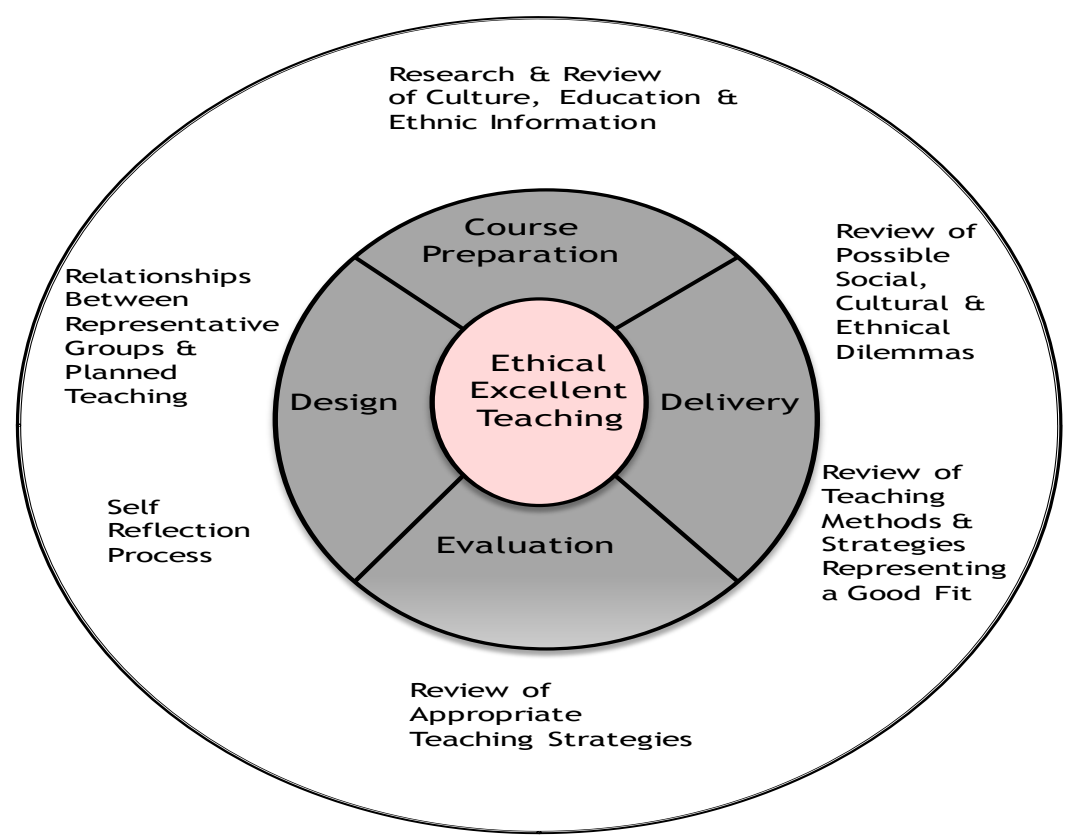

The outer circle in Graph 1 above represents a summary of the processes that are appropriate as instructional preparation for teaching multinational or multicultural groups in a classroom setting. The inner circle represents a summary of the classic instructional preparation model. As is indicated in the model, the additional preparation for multicultural groups does not supplant or replace the traditional preparation model. It is an overlay, or a series of additional steps, that must be taken in order to maintain excellence and ethical standards in the context.

\section{CONCLUSION}

Finally, the facilitation of the social-psychological process of learning, whether teacher or student-centered, must be undertaken with both cognitive skill and affect - more recently referred to as emotional intelligence - as equally important considerations. An overreliance on either side of this somewhat abstract equation will result in a less than effective classroom.

Further research in the area of trans-national and cross-cultural teaching needs to be undertaken. It is likely that major cultural groups, such as Asians, Central Americans, Eastern Europeans, and other cultural groupings around the globe, must be educated using specific methodologies in order for effective education to be realized. Moreover, qualitative research designs that provide specific, albeit non-generalizable, information are critical to gaining an understanding of what is necessary. Quantitative data based on student surveys may also be helpful in understanding the critical variables to be considered in the education process. However, one certainty remains; i.e. we cannot expect to teach homogeneous groups in the near or distant future, and education, like economics, politics, and other human endeavors, is becoming less local and more global with each passing day.

\section{AUTHOR INFORMATION}

Dr. Richard L. Henderson has teaching and administrative experience in private as well as public education and as a consultant for a variety of human service institutions and private corporations. He served as Coordinator for Educational Administration at the University of Texas at San Antonio. He served as Chair for Educational 
Administration and Supervision Graduate Programs at the University of Arkansas, Little Rock for six years where he also received the Faculty Excellence in Teaching award. His research and writing is published in international as well as national and regional journals.

Dr. Norman St. Clair currently serves as a member of the doctoral faculty and Director of Graduate Studies in the Dreeben School of Education at the University of the Incarnate Word (UIW). His fields of expertise and research agenda are focused in the areas of International Education and Entrepreneurship and Leadership. Before assuming his current responsibilities, Dr. St. Clair served as Director of International Initiatives for 5 years at UIW and was the founding On-site Academic Director for UIW's China Incarnate Word campus in Guangzhou, China, where he lived and served for 5 years.

Dr. Absael Antelo comes from a family of educators devoted to the advancement of education. He has extensive teaching and administrative experience in institutions of higher learning, common schools, and in business organizations both domestically and internationally. He has served as university president, school superintendent, academic vice president, university professor, and as an executive of a textile industrial group. Currently he is an Associate Professor and Coordinator of the Higher Education concentration in the Dreeben School of Education's $\mathrm{Ph} . \mathrm{D}$. program at the University of the Incarnate Word. His research agenda and publications include leadership, followership studies, and intercultural learning.

\section{REFERENCES}

1. $\quad$ Angelil-Carter, S. (2000). Stolen language?: Plagiarism in writing: New York: Longman.

2. Angelova, M \& Riazantseva, A (1999). 'If you don't tell me, how can I know?: A case study of four international students learning to write the U.S. way', Written Communication, vol.16, pp. 491-525.

3. Ashworth, P \& Bannister, P. (1997). 'Guilty in whose eyes?: University students' perceptions of cheating and plagiarism in academic work and assessment'. Studies in Higher Education [Online], vol. 22, pp. 187204. Accessed September 24, 2008.

4. Biggs, J. (1994). Asian learners through Western eyes: An astigmatic paradox. Australian and New Zealand Journal of Vocational Educational Research,2(2), 40-63.

5. $\quad$ Cameron, J 2004, 'George Bush cheats so why can't I'? Chaff, vol. 70, no.18, p.16.

6. Carroll, J. (2002). Suggestions for teaching international students more effectively. Learning and Teaching Briefing Papers Series, Oxford Brookes University. Retrieved September 24, 2008, from http://www.brookes.ac.uk/services/ocsd/2learntch/briefing-papers/international_students.pdf

7. Carroll, J. and Appleton, J. (2001). Plagiarism, A good practice guide [Online]. Available: http://www.jisc.ac.uk/uploaded_documents/brookes.pdf, retrieved September 24, 2008.

8. Cummings, R, Maddux, C D, Harlow, S, \& Dyas, L (2002). 'Academic misconduct in undergraduate teacher education students and its relationship to their principled moral reasoning', Journal of Instructional Psychology, vol. 29, pp. 286-296.

9. $\quad$ Drinan,P.(1999). Loyalty, learning, \& academic integrity. Liberal Education, 85(1), 28-34.

10. Fox, H. (1994). Listening to the world: Cultural issues in academic writing. Urbana, II: National Council of Teaching English.

11. Graham, M A, Monday, J, O'Brien, K, \& Steffan, S. (1994). 'Cheating at small colleges: An examination of student and faculty attitudes and behaviours', Journal of College Student Development, vol. 35, pp. 255260.

12. Hall, E. (1990). Understanding cultural differences. Yarmouth, ME: Intercultural Press.

13. Harris, R.A. (2001). The plagiarism handbook: Strategies for preventing, detecting, and dealing with plagiarism, Los Angeles: Pyrczak.

14. Henderson, Richard L. (1990) (translation: Absael Antelo) "The Study of Organization Theory: Avoiding Tacit Assumptions" El Estudio de la Teoria Organizacional: Evitando Asunciones Tacitas Investigacion Educativa: Universidad Autonoma del Noreste, Revista. 17. p. 6-23.

15. Hofstede.G. (2001). Culture's consequences ( ${ }^{\text {nd }}$ ed.). Thousand Oaks, CA: Sage.

16. Hunt, R. (2003). Four reasons to be happy about Internet plagiarism. Retrieved September 24, 2008, from http://www.stu.ca/ hunt/4reasons.htm. 
17. Lathrop, A. (2000). Student cheating and plagiarism in the Internet era: A wake-up call. Englewood, CO: Libraries Unlimited.

18. Marino, Gordon (February, 2004) "Teaching, Ethics, Theory” The Chronicle Review Vol. 50. Iss. 24. p. b5. Washington.

19. O’Donoghue, T. (1996). Malaysian Chinese students' perceptions of what is necessary for their academic success in Australia: A case study at one university. Journal of Further and Higher Education, 20, 67-80.

20. Pennycook, A. (1996). Borrowing others' words: Text, ownership, memory, and plagiarism. TESOL Quarterly, 30, 210-230.

\section{$\underline{\text { NOTES }}$}


NOTES 